\title{
Teaching risk-taking to engineering design students needs risk-taking
}

\begin{abstract}
Creativity is essential in the engineering design process to achieve innovative results. However, research has consistently shown that among the many factors that foster creativity in engineering education, one of the most central requirements is risktaking, which is not widely covered in engineering design education. This article attempts to understand the risk-taking approach in an engineering design education environment both from the students' and the instructors' perspective by conducting a qualitative comparative study in an Australian University. Overall, the study finds that instructors' teaching method has an influence on students' approach towards risk-taking. The evidence shows that engineering instructors are risk adverse and hesitate to adopt new approaches in education. However, fostering creativity in education requires a creative approach, which is possible through risk-taking. Encouraging engineering students to adopt a risk-taking approach during the design process is not possible until the engineering instructors and engineering faculties are willing to take risks in their own teaching methods.
\end{abstract}

\section{KEYWORDS}

risk-taking engineering design engineering education creativity teaching approach design process 


\section{INTRODUCTION}

Engineering is 'the design and development of technological solutions to problems' (Cropley 2015: 2). It is the ability to solve problems with a creative process (Zhou 2012a).

Cropley and Cropley (2010) describe creativity from an engineering perspective as 'functional creativity' to indicate the importance of functional requirements in the engineering field. Creativity 'helps engineers with complexity, it helps shape new knowledge, find new solutions to problems, engage in technologically innovative activities and lead to new designs' (Zhou 2012b: 99). This study, building on the works of many others, reviews and offers a definition of creative thinking (Amabile 1983; Cropley and Cropley 2010; Kazerounian and Foley 2007; Williams et al. 2010): Creativity empowers the engineer with ingenuity to tolerance for the unconventional so as to generate original and non-obvious alternatives, which ultimately lead to better, innovative and worthwhile solutions to design problems.

It is argued that education plays a role in relation to creativity (Cropley and Cropley 2010). However, teaching creativity to engineering students can be a challenging endeavour (de Vere 2009) and many researchers (Kazerounian and Foley 2007; Williams et al. 2010; Zhou 2012a) agree that it is still an issue to be addressed. Researchers believe that the best way to teach creative thinking skills is through the problem-solving processes (Kazerounian and Foley 2007; Williams et al. 2010).

Research has shown among the many factors that foster creativity in engineering education, risk-taking is one of them. Risk-taking enables students to try new things, which is crucial to the creative process (Piirto 2011; Treffinger et al. 2002). It is important to encourage risk-taking to foster creativity in engineering education (Kazerounian and Foley 2007). Piirto (2011) believes that risk-taking is a personality trait, and it might be difficult to encourage it, but it should not be discouraged by educators either. Sternberg (2007) also suggests that encouraging students to take risks also means not punishing them for making mistakes. Liu and Schonwetter (2004) described 'fear of failure' as a block to creativity. Risk-taking should become more common and it should be encouraged in the engineering educational context (Sahlberg 2009).

Not all disciplines treat risk-taking in the same way. Akin (2001) compares architecture and engineering in terms of risk-taking and argues that architects take risks, while engineers are not allowed to make any mistakes, which leads to the lack of risk-taking. Engineers believe that they cannot take risks like artists or musicians because they are building automobiles or bridges that can have profound life-changing consequences (Kazerounian and Foley 2007). When making risk-involving decisions, engineers are particularly concerned about safety (Ross and Athanassoulis 2010).

In an educational context, an essential factor that influences students' creative thinking and enhances risk-taking is the approach taken by instructors. The relationship between creative thinking, risk-taking and teaching strategy has been widely investigated. Some researchers believe that it is the responsibility of the educators to stimulate creative thinking among students (Kazerounian and Foley 2007; Richards 1998). However, this is not an easy task. This is because an instructor's teaching practices are shaped, in part, by their beliefs. For some, beliefs held around creativity need to be modified. Such a change is only possible by encouraging educators to develop new teaching methods (Henderson et al. 2011). Elisondo et al. (2013) argue that an 
unexpected teaching and learning context must be sustained as a strategy to promote creativity in education. This requires breaking the established practice or improvisation. 'Generating creative educational contexts also involves decisions and risks' (Elisondo et al. 2013: 14).

In his article, Serago describes the teaching method of Nadia Kellam, 'the role of risk-taking in the classroom' and examines 'how sustaining a mind-set of risk-taking in the classroom can produce engineering graduates ready and excited to tackle society's most pressing challenges' (Serago 2016). Professor Kellam believes that risk-taking 'prepares students to ask critical questions and produces graduates who pursue careers that promise to make an impact after graduation' (Serago 2016).

Assessing creativity in education is also worthy of consideration. Methods of assessment are abundant for assessing creativity. Treffinger et al. (2002) suggest a list of 'creativity characteristics': 'Generating ideas, digging deeper into ideas, openness and courage to explore ideas and listening to one's inner voice'. A well-known and highly cited assessment method by Besemer and O'Quin (1986), the Creative Product Semantic Scale, measures product creativity by three scales: Novelty, Resolution and Elaboration \& Synthesis. Another well-known creativity assessment method by Amabile (1983), the Consensual Assessment Technique, aims to ask people whether a product is creative or not. Charyton et al. (2011) provides a reliable and valid practical application in engineering education through their Creative Engineering Design Assessment, which assesses a person's design ideas expressed by sketching. Cropley's (2015) Creative Solution Diagnosis Scale (CSDS) is one of the newest creativity assessment methods and is easy to understand. It measures the 'kind of creativity' and 'amount of creativity' of engineering design products (Cropley 2015). First, the solution needs to be 'relevant and effective'. Second, the 'novelty' criterion leads to originality, which measures the newness of the solution. The third criterion'genesis offers new possibilities for the situation'. Finally, 'elegance is concerned with aesthetic aspects of the product' (Cropley 2015: 67-68).

Visser et al. (2017) evaluate the impact of feedback to support confidence and creativity from a graphic design perspective and they highlight the importance of informal class discussions and one-on-one feedback for effective learning. Ardington and Drury (2017) also underline the importance and positive impact of formative feedback and proper guidance in helping students learning their creative process in a design studio. In an engineering design subject, where students are expected to come up with a creative work is no different. Making feedback more explicit through dialogue should advance the way towards a more successful pedagogy (Ardington and Drury 2017: 167).

deVere (2009) highlighted the importance and relevance of Product Design Engineering (PDE) pedagogy for a response to the current educational issues and expectations of other engineering disciplines. de Vere (2009) suggests that engineering faculties (or departments) should see design pedagogy as a model for fostering creativity. Welch and Loy (2013) highlight that one of the most important teaching issues in design is finding a way to instil creative thinking in students' problem-solving process without overloading them with old approaches. To do this, 'a holistic approach to thinking, teaching and assessment is prerequisite' (Welch and Loy 2013: 92).

As risk-taking is not taught in any other subjects in the engineering curriculum, the design subjects are thought to be appropriate places to allow students to take risks. However, teaching risk-taking requires a different 
approach. This article argues that the engineering instructors should be involved in more risk-taking processes in their teaching and assessment approaches to enhance the risk-taking approach of their students.

\section{METHODS AND RESEARCH DESIGN}

The aim of this study is to shed new light on the instructor and faculty approach through an examination of engineering students' risk-taking habits in the classroom. In addition, the study aims to show the differences between the pedagogical approach of two engineering disciplines - Mechanical Engineering (ME) and Product Design Engineering (PDE) - and their approach to creativity and risk-taking. Therefore, this study makes a significant contribution to and review of engineering design education.

A qualitative approach was adopted for this study. The main data collection methods were classroom observations, surveys and interviews, allowing for triangulation to be achieved. The author observed two engineering design subjects from both ME and PDE disciplines for one academic calendar year. Both the PDE and ME design subjects drew upon problem solving as the primary mode of teaching and learning.

Below are the subjects studied and kind of method of data collection:

- $\mathrm{ME}$ - Machine Design (MD) and Mechanical Systems Design (MSD)

o Observations in lectures and in two tutorials

o Interviews with five instructors and six students

- PDE - PDE Studio and Advanced Product Design

o Observation in studio classes

o Interviews with three instructors and two students

Semi-structured interviews were conducted with the students and instructors of these subjects. Before conducting interviews, Written Student Surveys (SWS) were used in ME and PDE design subjects to collect general data on the creative design process such as the participants' understanding about creativity in engineering and engineering education context. After the semester ended, Student Feedback Surveys (SFS), sanctioned by the university, were also analysed. Learning materials for each subject, such as subject outlines, project briefs and rubrics, were also collected and examined as part of the analysis process.

Sources of data in this study include the following: enrolled students and subject coordinators and instructors in PDE and ME, and the researcher as participant observer. Each data source holds a key element to understanding the primary thesis: understanding risk-taking in the design process of engineering subjects.

\section{RESULTS}

The study found that in comparison to PDE students, ME students' approach to risk-taking during the design process is noticeably lacking. It was observed that ME students were not taking any risks in their problem-solving process and preferred to rely on proven methods. There is nothing wrong with this approach, if students were only expected to solve the problems as simple as possible with proven methods. However, as students were also expected to 
come up with creative ways of solutions, this can be problematic and therefore requires a willingness to engage in risk-taking.

Student Written Survey results show that student and instructor understandings about creativity in engineering education context are alike. Among the given characteristics, the majority indicated that 'innovative' represents creativity, which aligns with the author's creativity description. 95 per cent of the students agreed that creativity was important in their engineering education. However, the responses to whether creativity was taught and promoted in the ME design units had an equal number of 'Yes' and 'No's. ME students focused more on the exam, rather than on the design project. Although students found that the most effective part of the units were designing and building the projects, they spent most of the tutorial hours to get ready for the exam, not for developing their design projects. Students' responses also showed that in PDE design units they were expected to be creative, whereas in $\mathrm{ME}$ design units students just needed to solve the given problem; being creative was not valued.

SFS were conducted by the university and not specifically designed for creativity in engineering. Therefore, not all the information was relevant with this research. There were general issues and suggestions from the students about the organization of the design subjects. A majority of the students highlighted the lack of guidance and feedback during the design process to be improved in ME design subjects. Another highlighted point was the excess expectation from the students such as having both an exam and a design project as part of the same subject. After collecting data from the surveys, interviews were conducted to learn more about the above-mentioned issues.

During the design process, students were asked about their idea development process; one student (ME-S6) said that they consider a couple of alternatives but in the end, they 'ended up going with the one that [they] thought was simplest and was the best as far as the scoring system goes'. He or she then added: 'We just went with what worked' (ME-S6). This particular comment seems to suggest that students avoided risk-taking while developing their ideas further because of the possibility of failure. How, then, can students be encouraged to take risks for innovative solutions?

During the course of this research, the author, after observing and identifying the issues around risk-taking, suggested to the Subject Coordinator (SC) a series of evidence-based interventions, such as:

- Modifying the assessment of the design products

- Changing the format of the exam

- Giving students feedback during the design process

All of these actions were believed to enhance creativity and risk-taking among students. However, the SC and the tutors of the unit were reluctant to take risks about adopting these modifications. These interventions are explained in detail below:

\subsection{Modifying the assessment of the design products}

Both MD and MSD units have $40 \%$ worth of exam components. The majority of the students were working on designing a'gear box' in MD (Design performance 20\%, Project report 30\%) and a 'solar boat' in MSD (Design component $15 \%$, Project report 15\%). They were both assessed on their performance 
such as how much the gear-box lifted, or in how many seconds the solar-boat finished the route.

As ME subjects are design subjects, it is suggested that SC to increase the emphasis on the assessment of the design project and creative thinking. ME tutors were also consulted about this suggestion. They all agreed that the issue is the way in which marks are awarded for design. The instructors (ME-I1, ME-I3) agreed that the current assessment method does not encourage creativity: 'Students need to have some evidence of using creativity and applying it [...]. It needs to be more assessable' (ME-I5). ME-I1 argued that a certain percentage of the marks must be allocated to creativity. Similarly, ME-I3 suggests balancing the assessment weighting by allocating some marks to creativity and reliability.

Accounting for the design product's performance is a core feature of the assessment. This was apparent because in the subject outline, priority is given to the design product's performance rather than creativity. It is believed that this discourages students to take risks and engage in the creative process during the design process. One student indicated in the end-of-semester student survey (2015-MD-SWS) that his or her group were 'marked on success, not creativity, thus the risk of creating a creative design is too high'. Another student's comment reveals the reason why students do not take risks during the design process: 'If you try to keep it simple you decrease the chance of failure. Every complex item brings a chance of failure' (2015-MD-SWS).

During discussions with instructors, it was suggested to the SC to include creativity in the rubric of the design project, in addition to performance. To assess this, many different research-based creativity assessment methods were suggested. However, the SC said he or she was unsure about a proper way of judging creativity fairly. The biggest challenge that the SC pointed out was the difficulty in finding an objective assessment tool for the creativity of the projects that can easily be adopted by the instructors. The SC's other concern was that the assessment of creativity would be subjective: "This type of marking will be different from a performance mark where we use an independent system to provide a score. Whereas we need to be able to justify the mark we give' (SC). The'subjectivity of assessment in creativity' issue has been explained in detail in a previous study by the author (Tekmen-Araci and Mann 2019).

After conducting regular meetings with the SC, the CSDS - a creativity assessment method developed by Cropley and Cropley (2010) - was suggested to be used. Although the SC agreed to use this method in the MSD unit, he or she preferred to use it in an extra-curricular activity. Even though students were told that they were going to be assessed for creativity criteria, the SC did not want to risk using this method officially. This shows that even though the SC of the ME design subjects admitted that he or she was open to new and innovative methods in teaching, he or she was unwilling to make an application to a substantive piece of assessment. Students were encouraged to be involved in this extra-curricular activity and to assess each other based on the creativity of the projects. However, students did not take this assessment seriously as it was not going to be reflected on students' final assessment marks.

If instructors expect students to come up with creative solutions to the design problems, then they also need to encourage their students in creative thinking and it must be specified in the subject outline or in the assessment criteria as a formal requirement. However, amending the assessment of the design project from only'performance' to'performance and creativity' was seen as a risk from the instructor's perspective. This study implores engineering 
instructors to take risks in redesigning their assessment methods for their design subjects.

\subsection{Changing the format of the exam}

The emphasis on the final exam was another factor that affected students' design process, and implicitly their risk-taking appetite. With such a focus on the final exam, students are unable to benefit from working on their design process in tutorials.

To mitigate against this concern, the author suggested to the SC a change to the format of the exam or rather, simply abolish it all together. Such a move would encourage students to focus more on the design process as this is where creativity and risk-taking occur. Students in the end-of-semester survey indicated that a lot of their studying effort went into the final exam preparation. Students seem more worried about the final exam and did not give due priority to design and creativity. ME-I1 supports this claim by indicating that the exam was 40 per cent of a students' final mark and therefore warranted such preparation.

The SC explained that he or she was instructed by the faculty to have an end-of-semester exam in the design subjects. Historically this has been the case. The SC admitted that the faculty did not necessarily support the idea of abolishing the final exam. This approach shows that the faculty is unwilling to engage in alternative ways of teaching and learning, such as, not focusing on exams (at least in engineering design subjects).

It appears that ME instructors and the faculty are not risk takers as they hesitate to try new approaches in education. To enhance creativity in education requires risk-taking. As Sahlberg (2009: 343) claims 'creativity requires risk-taking and there is no innovation without risk-taking [...] Unless teachers feel free and safe to take risks in their work, they will not be able to take risks when they teach their students'.

If the aim is to enhance a student's creative thinking why insist on keeping exams in design subjects? Welch and Loy describe that creative learning is possible if there is 'never one, single correct outcome or solution' (2013: 94). The end result should not be predicted by the student or the instructor (Welch and Loy 2013). Focusing on open-ended design problems rather than exams is believed to enhance students' approach towards creative thinking and risk-taking.

During the interviews, ME-I1 declared 'in engineering there's always a formula, there's always a route to follow. Being able to see beyond the traditional way of doing things, that's creativity' (ME-I1). This comment supports the idea that an instructor can cultivate and enhance creativity in engineering education, and this is possible through risk-taking. Therefore, the study suggests that engineering instructors and the engineering faculties should adopt risk-taking in their teaching and assessment methods and not rely or depend on strict routes.

\subsection{Giving students feedback during the design process}

Another major theme that emerged from the findings was the lack of feedback from ME instructors during the design process. It was observed and confirmed by students that more guidance and feedback during their design process, creative sessions and in decision-making is needed. It proved challenging to convince most of the engineering instructors to give feedback to their students through this process. 
The study shows that ME instructors misunderstood the concept of 'guiding'. Some instructors thought that guiding students was equal to making all the decisions on behalf of their students. Some of them did not want to be involved much in students' work because they thought this was not fair. However, SFS results showed how feedback could have helped students: 'I still feel like this whole part was taught by throwing us in at the deep end and hoping we get better. Some guidance on things like useful strategies to adopt would have been good' (2015-MD-SFS). 'Being presented with an abstract problem without any guidance is very shocking' (2015-MD-SFS). A PDE student put forward the issue in ME design subjects: 'Minimal instructor support in reference to design as compared to other design subjects' (2015MD-SWS).

When students were asked how they preferred to be treated in ME tutorials, PDE-S1 said that they preferred to be checked regularly: 'In PDE we've always been given guidance and encouragement about how to push the design further [...] It not only keeps you up to date, it also pushes you to make a good product' (PDE-S1). It was apparent that PDE students were able to develop their ideas based on the feedback that they received from their instructors.

Interestingly, even when the students declared that they wanted more feedback for their projects, instructors were hesitant about giving more feedback. Instructors were asked whether they regularly followed the development of students' design projects and whether they gave feedback; ME-I5 admitted that he or she tried to go around and talk to each team about their design projects. However, if students did not want to talk, he or she would not persist. The author observed in tutorials that the instructor did not go much beyond asking students whether 'they had any "issues" regarding their projects'? Often, students responded that they had 'no issues'. The observations were consistent with those of instructors, who stated: 'You don't want to be assessing everyone's design every week to say where is it, how is it going, how do you feel about it [...] unless they specifically are struggling I don't step in' (ME-I4). He or she added that students 'are already a team of grown-ups [...] We are talking about engineers who are almost at the end of their education. They need to work on something alone without someone guiding their every step' (ME-I4).

Guiding students and providing feedback should not be understood as just prescriptive. For example, in PDE the instructors did not tell students what to do; rather, they guided them by coaching, facilitating and supporting them in their problem-solving process. Students should be given regular and iterative feedback to confirm they are on the right track. Feedback helps students 'by providing the best possible information to the student through identifying and explaining elements of creativity that apply to a particular process or product' (Welch and Loy 2013: 97). Giving regular feedback to students provides a safe environment where students can ask questions and become involved in the discussion about the creativity of their concepts. It also allows for a safe environment to take risks and safe opportunities to fail during the design process. These findings confirm what Cropley (2015: 231) suggests, 'creativity can be fostered and developed through specific activities and with appropriate guidance'. Similarly, Daly et al. (2014) indicate that instructors could give more feedback to their students. This is because providing feedback to students will help them control their own learning process (Pollock et al. 2015). 


\subsection{Difference between the two disciplines about risk-taking}

Substantial differences were observed between PDE and ME about the student and instructor approaches towards risk-taking.

Both discipline's instructors admit that they encourage creativity and risktaking. However, ME students' approach towards risk-taking was observed to be less because they thought that if they fail, there would be no mark for it. As PDI-I1 cogently argues 'creativity is risk-taking'. ME-I1 provided an interesting explanation at the end of the semester between the simpler and more complex student submissions: the common gear-box designs in MD performed better and received higher marks; however, the creative submissions that were more complicated did not perform well and therefore received low marks (ME-I1). ME-I1 explains that the reason why the students did not take any risks for creativity is because 'If there is a good mark for it [creativity], then everybody will know that this is all about creativity. But now it's just about performance'.

Upon reviewing the subject outlines, it became apparent that in $\mathrm{ME}$, the final design products were assessed according to their performance. In other words, if the products worked poorly the marks were lower; if it did not work students would fail. However, in PDE design subjects, students were assessed not only for their final design products but also for their design process. The ideas that they came up with during that process were as important as the final product. This assessment approach encouraged students to push boundaries and to take further risk towards trying innovative ways to solve the problems.

PDE-I1 indicated in an interview that he or she is a fan of evaluating the creative process in a learning context:

Creativity is about taking a risk that is harder in educational contexts [...] I tend to favour my process and the students' ability to try lots of variables, lots of solutions to the problem. [...] Creativity is essential for problem solving but also for risk-taking [...] If someone works through the process thoroughly, that ranks more heavily on the final grading than the actual outcome.

(PDE-I1)

The current evidence seems to suggest that ME instructors did not encourage or allow students to take risks for creative thinking. In the ME context, 'the product has to work in the end' (ME-I1). This approach harnesses many constraints. Most students prefer to play it safe by not taking risks. This is because students can meet the expectations with a working solution since there is no reward in taking risks. On the other hand, PDE instructors are not satisfied with just a working solution; they also expect to see some creativity. PDE students were aware of this assessment component and therefore were less afraid of failing, which created the conditions necessary to take risks. A student, who took both ME and PDE design subjects, compared the two approaches:

In PDE we spend a lot more time through ideation and the earlier stages where you develop the idea. Whereas in ME, we come up with an idea that we're satisfied with and then we refine just that idea and try to make it as functional as possible. 
An important difference between these two subjects is in the exams. PDE design subjects did not involve any exams whereas ME design subjects had a 40 per cent exam. This again shows the different approach of the PDE discipline towards creativity teaching and learning. When PDE instructors were asked why there was no exam for PDE design subjects, PDE-I1 said:

It's very hard with a design process to have an exam. Oral presentation is like an exam. It is about explaining your product outcome, how you verify, how it sits compared to the competitor, how it may be sustainable, how you used your calculations to verify.

(PDE-I1)

Because there was no exam, students focused more on the design process, which allowed them to take risks.

These occasions show how the different approaches of PDE and ME affect student experience in terms of creative thinking and risk-taking. As de Vere (2009) suggests, engineering education should look at design pedagogy to enhance creativity.

\section{CONCLUSION}

This study contributes towards research on the risk-taking approach of the instructors in engineering design education. It argues that engineering instructors should take risks in their educational methods to enhance their students' creativity and risk-taking. In other words, instructors should be modelling the risk-taking approach to encourage their students to become risk-takers.

Blum (1990) presents an old but an inspirational example: Professor Matson's design subject from University of Houston 'Innovative Design for Civil Engineers'. The subject was known by his students as 'Failure 101'; this is because it 'focuses on risk, failure, and approaching design as a creative skill'. Matson suggests recognizing the role of failure in learning and creativity processes, not just the success. What Professor Matson does is to encourage his students 'to take risks and be creative'. He does this by having no lectures, or tests but occasional competitions and fun in class (Blum 1990). This certainly is a creative approach to teaching and needs a risk-taking approach to apply it. More of these kinds of approaches are required in engineering education.

Learning from failure is only possible by allowing students the opportunity to fail, in other words, to allow risk-taking. One of the best examples for inspiration is The Museum of Failure, which is'a collection of interesting innovation failures' from around the world, providing 'insight into the risky business of innovation' (2018).

Engineering Professor Kellam at ASU says that a revolution in engineering education can only be possible by introducing a risk-taking culture. By encouraging academic staff to get out of their comfort zone and to try new approaches, risk-taking becomes possible. However, if instructors maintain a fear of taking risks, this will affect their teaching methods and will not allow them to take risks that might be useful for students (Serago 2016). The instructors should also remember that students are still in an education context; therefore, students should not be punished for failing. Failure is always an inherent part of the learning process. Engineering design education needs to embrace this notion when assigning project tasks to students. The best place to learn from failure is in a comfortable and safe educational environment; risks are not as severe as the ones done in the professional world. 
Trying something new for the first time in an institution - even when it is grounded in peer-reviewed research - always has the potential of being risky. This is because it is new and being applied, potentially, for the first time. If instructors and faculties continue to avoid risk-taking in their teaching, the opportunity to enhance creativity and risk-taking in engineering education will continue to be unachievable.

Owen (2014) describes a charismatic leader who is not afraid of taking risks and to challenge traditional approaches. Educators must be risk-taking leaders and they must also be supported by their disciplines. As long as educators continue to remain conservative in their teaching approaches, opportunities to enhance creativity in engineering education will continue to be a challenge.

\section{REFERENCES}

Akin, Ö. (2001), 'Variants in design cognition', in C. Eastman, M. McCracken and W. Newstetter (eds), Design Knowing and Learning: Cognition in Design Education, Oxford: Elsevier Science, pp. 105-24.

Amabile, T. M. (1983), 'The social psychology of creativity: A componential conceptualization', Journal of Personality and Social Psychology, 45:2, pp. 357-76.

Ardington, A. and Drury, H. (2017), 'Design studio discourse in architecture in Australia: The role of formative feedback in assessment', Art, Design $\mathcal{E}$ Communication in Higher Education, 16:2, pp. 157-70.

Besemer, S. and O'Quin, K. (1986), 'Analyzing creative products: Refinement and test of a judging instrument', The Journal of Creative Behavior, 20:2, pp. 115-26.

Blum, E. (1990), 'Risk taking encouraged: In failure 101, University of Houston Engineering Professor offers an innovative and creative approach to design', The Chronicle of Higher Education, 36:30, pp. A15-20.

Charyton, C., Jagacinski, R. J., Merrill, J. A., Clifton, W. and DeDios, S. (2011), 'Assessing creativity specific to engineering with the revised creative engineering design assessment', Journal of Engineering Education, 100:4, pp. 778-99.

Cropley, D. (2015), Creativity in Engineering: Novel Solutions to Complex Problems, New York: Elsevier.

Cropley, D. and Cropley, A. J. (2010), 'Recognizing and fostering creativity in technological design education', International Journal of Technological Design Education, 20:3, pp. 345-58.

Daly, S. R., Mosyjowski, E. A. and Seifert, C. M. (2014), 'Teaching creativity in engineering courses', Journal of Engineering Education, 103:3, pp. 417-49.

de Vere, I. (2009), 'Developing creative engineers: A design approach to engineering education', International Conference on Engineering and Product Design Education, University of Brighton, UK, 10-11 September.

Elisondo, R., Donolo, D. and Rinaudo, M. C. (2013), 'The unexpected and education: Curriculums for creativity', Creative Education, 4:12B, pp. 11-15.

Henderson, C., Beach, A. and Finkelstein, N. (2011), 'Facilitating change in undergraduate STEM Instructional Practices: An analytic review of the literature', Journal of Research in Science Teaching, 48:9, pp. 952-84.

Kazerounian, K. and Foley, S. (2007), 'Barriers to creativity in engineering education: A study of instructors and students perceptions', Journal of Mechanical Design, 129:7, pp. 761-68.

Liu, Z. and Schonwetter, D. (2004), 'Teaching creativity in engineering education', International Journal of Engineering Education, 20:5, pp. 801-08. 
Museum of Failure (2018), 'Museum of failure', http://failuremuseum.com. Accessed 25 July 2018.

Owen, C. (2014), '“Forget everything you have ever learned about art, and start from the beginning": Charismatic leadership and art school teaching', Art, Design \& Communication in Higher Education, 13:2, pp. 201-14.

Piirto, J. (2011), Creativity for 21st Century Skills: How to Embed Creativity into the Curriculum, Rotterdam: Sense Publishers.

Pollock, V. L., Alden, S., Jones, C. and Wilkinson, B. (2015), 'Open studios is the beginning of a conversation: Creating critical and reflective learners through innovative feedback and assessment in Fine Art', Art, Design $\mathcal{E}$ Communication in Higher Education, 14:1, pp. 39-56.

Richards, L. G. (1998), 'Stimulating Creativity: Teaching engineers to be innovators', $28^{\text {th }}$ Annual FIE Conference, Tempe, AZ, US, 4-7 November.

Ross, A. and Athanassoulis, N. (2010), 'The social nature of engineering and its implications for risk taking', Science Engineering Ethics, 16:1, pp. 147-68.

Sahlberg, P. (2009), 'The role of education in promoting creativity: Potential barriers and enabling factors', in E. Villalba (ed.), Measuring Creativity, Bruxelles: European Commission, pp. 337-44.

Serago, R. G. (2016), 'Should engineers take more risks in the classroom? Skydiving professor says yes', Arizona State University, https://asunow.asu. edu/20160405-solutions-should-engineers-take-more-risks-classroomskydiving-professor-says-yes. Accessed 15 June 2018.

Sternberg, R. J. (2007), 'Creativity as a habit', in A. Tan (ed.), Creativity: A Handbook for Teachers, Singapore: World Scientific, pp. 3-25.

Tekmen-Araci, Y. and Mann, L. (2019), 'Instructor approaches to creativity in engineering design education', Proceedings of the Institution of Mechanical Engineers, Part C; Journal of Mechanical Engineering Science, 233:2, pp. 395-402.

Treffinger, D. J., Young, G. C., Selby, E. C. and Shepardson, C. (2002), Assessing Creativity: A Guide for Educators, Sarasota, FL: The National Research Center on the Gifted and Talented.

Visser, I., Chandler, L. and Grainger, P. (2017), 'Engaging creativity: Employing assessment feedback strategies to support confidence and creativity in graphic design practice', Art, Design \& Communication in Higher Education, 16:1, pp. 53-67.

Welch, D. and Loy, J. (2013), 'A brave new creativity', Art, Design E Communication in Higher Education, 12:1, pp. 91-102.

Williams, A., Ostwald, M. and Askland, H. H. (2010), 'Assessing creativity in the context of architectural design education', Proceedings of Design Research Society 2010, Montreal, Canada, 7-9 July.

Zhou, C. (2012a), 'Fostering creative engineers: A key to face the complexity of engineering practice', European Journal of Engineering Education, 37:4, pp. 343-53.

(2012b), 'Teaching engineering students creativity: A review of applied strategies', Journal on Efficiency and Responsibility in Education and Science, 5:2, pp. 99-114.

\section{SUGGESTED CITATION}

Tekmen-Araci, Y. (2019), 'Teaching risk-taking to engineering design students needs risk-taking', Art, Design \& Communication in Higher Education, 18:1, pp. 67-79, doi: 10.1386/adch.18.1.67_1 


\section{CONTRIBUTOR DETAILS}

Yasemin Tekmen-Araci received her Ph.D. from Swinburne University of Technology in Australia in 2018. She has Master's and Bachelor's degrees in Industrial Design from Middle East Technical University. Yasemin has more than ten years of experience in teaching creative art and design studio subjects in different universities. Currently, she is working as a Learning Designer in Faculty of Engineering and IT at University Technology Sydney.

Contact: Faculty of Engineering and IT, University of Technology Sydney, City Campus, Building 11, P.O. Box 123, Broadway, NSW 2007, Australia.

E-mail: yasemin.tekmenaraci@uts.edu.au; yasemintekmen@gmail.com

으 https://orcid.org/0000-0001-8498-2280

Yasemin Tekmen-Araci has asserted her right under the Copyright, Designs and Patents Act, 1988, to be identified as the author of this work in the format that was submitted to Intellect Ltd. 


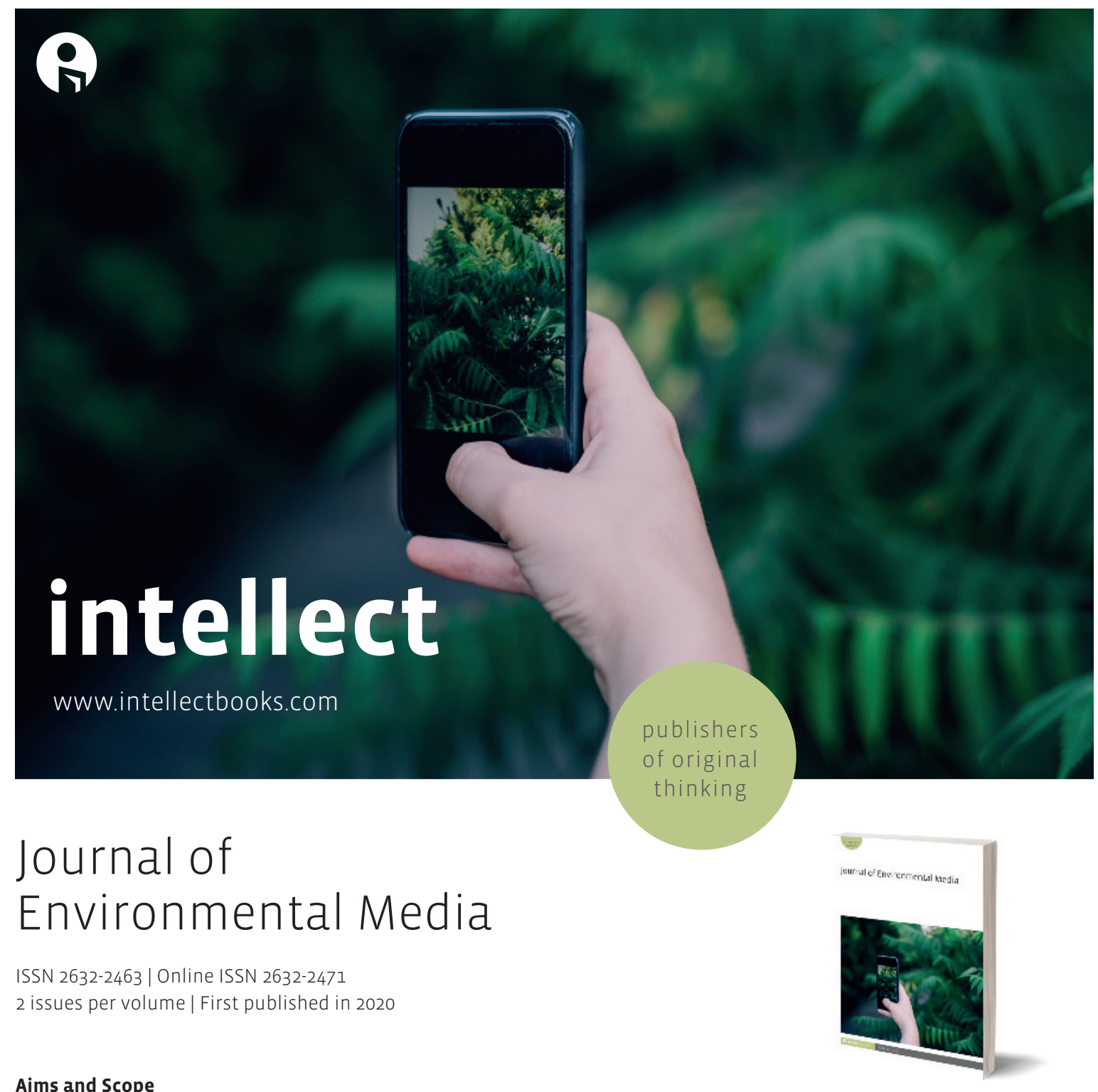

\section{Aims and Scope}

The Journal of Environmental Media (JEM) explores the role of digital culture and emergent media in shaping environmentally-themed content and activism, communicating environmental data and impacting social perceptions of the environment. JEM is a scholarly platform aimed at bridging work in environmental studies, digital culture studies, environmental justice, media industry studies, science and technology studies, media anthropology and environmental communication, covering a range of environmental issues such as climate change, environmental racism, renewable and fossil fuel infrastructures, species extinction, climate migration and e-waste. We promote work that engages with diverse methodological and disciplinary approaches, bringing social science research into dialogue with environmental humanities discourses on production cultures, screen studies and environmental justice. JEM includes a broad landscape of media forms and practices, including smart technology, machine learning, popular media and streaming services, social media platforms, apps and new developments in augmented reality and virtual reality. 
Copyright of Art, Design \& Communication in Higher Education is the property of Intellect Ltd. and its content may not be copied or emailed to multiple sites or posted to a listserv without the copyright holder's express written permission. However, users may print, download, or email articles for individual use. 